\title{
Uniform versus Discriminatory Tariffs: When Will Export Taxes Be Used?
}

\author{
Pei-Cheng Liao* and Kar-yiu Wong $\dagger$
}

\begin{abstract}
This paper examines the noncooperative interactions between two exporting countries and one importing country when all of them are seeking the optimal policies to improve their welfare. Whereas the importing country has the incentive to impose tariffs on the goods coming from the two exporting countries, the export policies chosen by the exporting countries depend on the tariff regime, whether uniform or discriminatory tariffs are used. It is argued that export taxes are chosen by both exporting countries in some cases, and that whereas the importing country prefers a uniform tariff regime, the exporting countries find a discriminatory tariff regime preferable.
\end{abstract}

\section{JEL Classification: F12, F13}

\section{Introduction}

This paper attempts to combine two branches of strategic trade policy literature together by analyzing choices of export subsidies and import taxes in a unified framework. It aims to provide a better insight into the interactions among the governments of two exporting countries and an importing country.

In a seminal paper, Brander and Spencer (1985) show that under Cournot competition a domestic export subsidy allows a domestic firm to gain at the expense of a rival firm in another exporting country. Their paper initiated a great deal of interest in the proper use of export subsidies. ${ }^{1}$ It is noted that in the Brander-Spencer and related models, the government of the third country, which imports the goods from the two countries, is assumed to be inactive. On the other hand, there is a separate literature that analyzes the optimal policies for an importing country, which buys a homogeneous product from two countries with rival firms. For example, Gatsios (1990) and Hwang and Mai (1991) show that the optimal policy for the importing country is to impose a higher tariff on the product from the more cost-efficient exporter. Choi (1995) and Horiba and Tsutsui (2000) extend the literature by comparing the impacts of discriminatory and uniform tariffs. Both of these two papers examine the choice of the two tariff regimes by the importing country, and investigate how a regime may affect

* Department of Accounting, National Taiwan University, No. 1, Sec. 4, Roosevelt Road, Taipei 106, Taiwan; E-mail: pcliao@ntu.edu.tw.

$\dagger$ Department of Economics, University of Washington, Box 353330, Seattle, WA 98195, USA; E-mail; karyiu@u.washington.edu; corresponding author.

This paper was presented at National Taipei University, Taiwan. Thanks are due to the participants for very useful comments. All remaining errors and shortcomings are the responsibilities of the authors.

Received June 2003; accepted January 2005.

${ }^{1}$ It has been shown that Brander and Spencer's result is sensitive to some of the assumptions in the model. For example, Eaton and Grossman (1986) argue that if the firms compete in a Bertrand way, the optimal domestic policy is an export tax. Horstmann and Markusen (1986) consider the case of integrated markets with free entry and find that an export subsidy is welfare-deteriorating. See, for example, Wong (1995) and Brander (1995) for recent discussion of the use of some of these strategic policies. 
the level of technologies chosen by the exporting firms. All these papers focus on the policies of the importing country, while assuming that the exporting governments are inactive.

In this paper, we consider a model similar to those examined by all these papers: two exporting countries and one importing country, with one firm in each of the exporting countries competing in a Cournot way. What makes the present paper different from others is that we allow all three governments to be active in choosing the optimal values of their policies: an export subsidy/tax for each exporting country and a tariff/subsidy for the importing country. We also analyze the impacts of two different tariff regimes: a uniform tariff regime, as required by the Most-Favored-Nations (MFN) clause of the GATT/WTO, and a discriminatory tariff regime. Choosing between these two types of tariff regimes is an interesting issue in the present framework, because it not only determines the welfare of the importing country, but also affects the export subsidies chosen by the exporting countries. The present, more extensive model and analysis, as compared with what exists in the literature, can be used to answer several questions. If each exporting country is aware of the tariffs to be imposed by the importing country on the products from itself and its rival, does it still have an incentive to impose an export subsidy, as Brander and Spencer proposed? Does such an export subsidy depend on whether the importing country is using discriminatory tariffs or a uniform tariff? How might the noncooperative equilibrium in terms of export subsidies be affected by the tariff regimes chosen by the importing country? What is the optimal tariff of the importing country in response to the export subsidies chosen by the exporting countries? How would the importing country choose between the two tariff regimes? How would the welfare of these countries be affected by the policies and the policy regimes?

Some of the results obtained in the present paper can be linked to the existing results. Under a uniform tariff regime, as required by the MFN clause, the Brander-Spencer argument kicks in, and each country has the right incentive to promote the export of its own firm with an export subsidy. If the importing country is using discriminatory tariffs, the argument in the papers by Gatsios (1990), Hwang and Mai (1991), Choi (1995), and Horiba and Tsutsui (2000) is applicable: An importing country tends to impose a higher tariff on the more cost-efficient exporter. Thus, in our model, there are two forces that affect the export subsidy chosen by an exporting country: the profit-shifting argument of Brander and Spencer, and the tariff effect that tends to induce each government to raise the effective marginal cost of its own firm in order to avoid a higher tariff. As a result, the actual export subsidy can be negative. We also compare the uniform tariff and discriminatory tariff regimes in terms of the welfare of the countries. We find that, at least in the case when the two exporting countries are identical, the importing country would choose a uniform tariff regime, whereas the export countries would prefer a discriminatory tariff regime. ${ }^{2}$

The present model assumes that the importing country chooses the tariff regime before, but the actual tariff rates after, the exporting countries' choice of their export subsidy policies. It is based on the assumption that it is easier for the importing country to set its tariff rate, but that the tariff regime, which represents the country's international commitment or its position in an international setting, for example, whether it has to follow the MFN clause of GATT/WTO, cannot be changed so easily. Obviously, a change in the order of the government policies could lead to different results. For example, Gatsios (1990) considers a model in which the importing and exporting countries set their policies simultaneously, and finds that the optimal policy for each exporting country is an export

\footnotetext{
${ }^{2}$ This paper does not analyze the impacts on the world welfare. In an interesting paper with a model of $n$-country and intraindustry trade, Saggi (2004) finds that each country has no incentive to adopt MFN unilaterally, but that MFN adoption by each country increases world welfare. Assuming a linear demand, he shows that MFN adoption by the country with the average production cost benefits the world most. Moreover, he examines the welfare effects of selective MFN and reciprocal MFN.
} 
subsidy. Moreover, with identical costs for the firms, he finds that all the three countries are indifferent to the tariff regimes.

The remainder of the paper is organized as follows: Section 2 describes the assumptions of the model and the features of a four-stage game. Sections 3 and 4 analyze the equilibrium of a game under a uniform tariff regime and a discriminatory tariff regime, respectively. Section 5 compares the two tariff regimes in terms of the welfare of all three countries. Section 6 provides a brief summary and some concluding remarks.

\section{The Model}

We consider a one-product, two-firm, three-country model. Two of the countries, which are labeled 1 and 2, have a firm producing a homogeneous product to be exported to the third country, $M$. There is no other producer of this product in country $M$ and there is no consumption of this product in the two exporting countries. Demand in country $\mathrm{M}$ is given by the inverse demand function, $p=p(Q)$, where $p$ is the market price. We assume $p($.$) is decreasing and twice continuously differentiable with$ $p^{\prime \prime}(Q) Q+p^{\prime}(Q)<0$, where a prime after a variable represents a derivative. ${ }^{3}$ The output of firm $i$, the one in country $i$, is denoted by $q_{i}, i=1,2$. So in equilibrium $Q=q_{1}+q_{2}$. Firm $i$ has a constant marginal cost, $c_{i}$, and a fixed cost, $f_{i}$. For simplicity, fixed $\operatorname{cost} f_{i}$ is set to zero because it will not affect the equilibrium of the game. All technology and demand information is known to all parties.

The governments of all three countries are active in setting policy parameters to improve the welfare of its economy. The government of each exporting country considers an export subsidy (may be negative), whereas the importing country, $M$, chooses a tariff. Facing the goods from countries 1 and 2, country $M$ can choose to impose the same tariff rates on these goods, the so-called MFN clause, or choose to impose different tariff rates on the goods from different countries. In order to analyze how the exporting countries may respond to these two types of tariff treatments, it is assumed that country $M$ has announced credibly whether it is going to impose a uniform tariff rate or differential tariff rates. After the governments have announced their policies, the firms compete in a Cournot way.

To analyze the interactions among the countries, we consider the following four-stage, one-shot noncooperative game. In the first stage, country $M$ announces whether it is using a uniform tariff regime or a discriminatory tariff regime. In the second stage, the two exporting countries choose their export subsidies, $s_{1}$ and $s_{2}$, simultaneously and noncooperatively. In the third stage, after observing the export subsidies, country $M$ imposes tariffs according to the tariff regime it announced in the first stage. All government announcements are credible and cannot be reversed. In the fourth stage, the two firms compete in quantities in the market of country $M$. To make our analysis interesting, we assume that the market in country $\mathrm{M}$ is big enough so that both firms are willing to produce a positive output under all policy parameters chosen by the governments. ${ }^{4}$ In what follows, we analyze the two tariff regimes separately. The two regimes are then compared in terms of the welfare of the importing country and the exporting countries.

\footnotetext{
${ }^{3}$ The assumption that $p^{\prime \prime}(Q) Q+p^{\prime}(Q)<0$, which is satisfied if the demand curve is not too convex to the origin, is made to ensure a declining marginal revenue curve.

${ }^{4}$ As a matter of fact, country $M$ would never want to impose a prohibitive tariff, and each exporting country would want to use an export subsidy to promote its own export, but usually would not want to drive the other firm out of the market.
} 


\section{Optimal Export Subsidy Policy under Uniform Tariff Regime}

Denote the uniform specific tariff imposed by country $\mathrm{M}$ by $\hat{t}$, and the exporting countries know that a uniform tariff will be imposed. The game is solved by backward induction. In the fourth stage, taking the specific export subsidies, $s_{1}$ and $s_{2}$, and the uniform tariff $\hat{t}$ as given, firm $i$ maximizes its following profit:

$$
\pi_{i}=\left[p(Q)-c_{i}+s_{i}-\hat{t}\right] q_{i}, \quad i=1,2
$$

The first-order condition for each firm to choose the optimal quantity is

$$
\frac{\partial \pi_{i}}{\partial q_{i}}=p^{\prime} q_{i}+p-c_{i}+s_{i}-\hat{t}=0 .
$$

Define $a_{i j} \equiv \partial^{2} \pi_{i} / \partial q_{i} \partial q_{j}, i, j=1,2$. Using the assumption $p^{\prime \prime} Q+p^{\prime}<0$, the second-order condition $a_{i i}=p^{\prime \prime} q_{i}+2 p^{\prime}<0$ is satisfied. In addition, $a_{i j}=p^{\prime \prime} q_{i}+p^{\prime}<0$, implying that quantities are strategic substitutes under Cournot competition. Moreover, the "stability" condition $\Delta_{1} \equiv a_{11} a_{22}-a_{12} a_{21}=$ $p^{\prime} p^{\prime \prime} Q+3\left(p^{\prime}\right)^{2}>0$ is satisfied. By solving the two first-order conditions in Equation 1 simultaneously, we can derive the Cournot equilibrium outputs $q_{1}^{*}\left(s_{1}, s_{2}, \hat{t}\right), q_{2}^{*}\left(s_{1}, s_{2}, \hat{t}\right)$, and $Q^{*}\left(s_{1}, s_{2}, \hat{t}\right)=$ $q_{1}^{*}\left(s_{1}, s_{2}, \hat{t}\right)+q_{2}^{*}\left(s_{1}, s_{2}, \hat{t}\right)$. Totally differentiating Equation 1 , we can get the following comparative statics results:

$$
\begin{aligned}
& \frac{\partial q_{i}^{*}}{\partial \hat{t}}=\frac{p^{\prime \prime}\left(q_{j}^{*}-q_{i}^{*}\right)+p^{\prime}}{\Delta_{1}}<0, \\
& \frac{\partial q_{i}^{*}}{\partial s_{i}}=-\frac{p^{\prime \prime} q_{j}^{*}+2 p^{\prime}}{\Delta_{1}}>0, \quad i, j=1,2 \text { and } i \neq j \\
& \frac{\partial q_{j}^{*}}{\partial s_{i}}=\frac{p^{\prime \prime} q_{j}^{*}+p^{\prime}}{\Delta_{1}}<0,
\end{aligned}
$$

where the signs are based on the assumption that the demand function is not too concave. Equations $2.1,2.2$, and 2.3 show that the uniform tariff affects negatively the output of each firm, whereas each export subsidy will promote its country's export but hurt the export of the other country. Furthermore, Equation 2.1 implies that $\partial Q^{*} / \partial \hat{t}=2 p^{\prime} / \Delta_{1}<0$, and adding Equations 2.2 and 2.3 gives $\partial Q^{*} / \partial s_{i}=-p^{\prime} / \Delta_{1}>0$.

In the third stage, country $M$ chooses $\hat{t}$ to maximize its welfare. Its welfare is given by the sum of the consumer surplus and tariff revenue:

$$
W_{M}^{u}\left(s_{1}, s_{2}, \hat{t}\right)=\int_{0}^{Q^{*}\left(s_{1}, s_{2}, \hat{t}\right)} p(x) d x-p\left(Q^{*}\left(s_{1}, s_{2}, \hat{t}\right)\right) Q^{*}\left(s_{1}, s_{2}, \hat{t}\right)+\hat{t} Q^{*}\left(s_{1}, s_{2}, \hat{t}\right) .
$$

The first-order condition for maximization is given by

$$
\frac{\partial W_{M}^{u}}{\partial \hat{t}}=-p^{\prime} Q^{*} \frac{\partial Q^{*}}{\partial \hat{t}}+Q^{*}+\hat{t} \frac{\partial Q^{*}}{\partial \hat{t}}=0
$$

The second-order condition $\partial^{2} W_{M}^{u} / \partial \hat{t}^{2}<0$ is assumed. The solution to the first-order condition (Eqn. 3) is

$$
\hat{t}^{*}=-\frac{1}{2}\left(p^{\prime \prime} Q^{*}+p^{\prime}\right) Q^{*}>0
$$

In the second stage, each exporting country chooses its export subsidy, taking the other country's export subsidy as given and being fully aware of how its export subsidy may affect the tariff rate and 
firms' outputs later. The national welfare of each exporting country is given by the profit of the firm, less the export subsidy payment:

$$
W_{i}^{u}\left(s_{1}, s_{2}\right)=\left[p\left(Q^{*}\right)-c_{i}+s_{i}-\hat{t}^{*}\right] q_{i}^{*}-s_{i} q_{i}^{*}, \quad i=1,2 .
$$

The first-order condition for the optimal export subsidy is given by

$$
\begin{aligned}
\frac{\partial W_{i}^{u}}{\partial s_{i}} & =-q_{i}^{*} \frac{\partial \hat{t}^{*}}{\partial s_{i}}-s_{i}\left(\frac{\partial q_{i}^{*}}{\partial \hat{t}} \frac{\partial \hat{t}^{*}}{\partial s_{i}}+\frac{\partial q_{i}^{*}}{\partial s_{i}}\right)+p^{\prime} q_{i}^{*}\left(\frac{\partial q_{j}^{*}}{\partial \hat{t}} \frac{\partial \hat{t}^{*}}{\partial s_{i}}+\frac{\partial q_{j}^{*}}{\partial s_{i}}\right)=0 \\
i, j & =1,2 \text { and } i \neq j
\end{aligned}
$$

Define $b_{i j} \equiv \partial^{2} W_{i}^{u} / \partial s_{i} \partial s_{j}, i, j=1,2$. The second-order conditions $b_{11}<0, b_{22}<0$ and the stability condition $\Delta_{2} \equiv b_{11} b_{22}-b_{12} b_{21}>0$ are all assumed to ensure global uniqueness of the Nash equilibrium in the export subsidy policy game. Denote the export subsidy chosen by country $i$ under a uniform tariff regime by $s_{i}^{u}$. From Equation 4, we can get

$$
s_{i}^{u}=\frac{q_{i}^{*}\left[p^{\prime}\left(\partial q_{j}^{*} / \partial s_{i}\right)+\left(p^{\prime} \partial q_{j}^{*} / \partial \hat{t}-1\right)\left(\partial \hat{t}^{*} / \partial s_{i}\right)\right]}{\left(\partial q_{i}^{*} / \partial \hat{t}\right)\left(\partial \hat{t}^{*} / \partial s_{i}\right)+\left(\partial q_{i}^{*} / \partial s_{i}\right)}>0, \quad i, j=1,2 \text { and } i \neq j
$$

By using Brander and Spencer's (1985) result, we are able to determine the positive sign of $s_{i}^{u}$ without going further to prove it. ${ }^{5}$ In the Brander-Spencer model, the case for a positive export subsidy does not depend on the cost of production. In the present model, a uniform specific tariff acts like an increase in marginal cost for both firms. As a result, under a uniform tariff regime, the usual profit-shifting argument can still be used and the optimal policy for each exporting country is an export subsidy. ${ }^{6}$

\section{Optimal Export Subsidy Policy under Discriminatory Tariff Regime}

Now we examine a discriminatory tariff regime. Denote the specific import tariff imposed by country $\mathrm{M}$ on the goods from country $i$ by $t_{i}, i=1,2$. The game is again solved by backward induction. In the fourth stage, taking the export subsidies $\left(s_{1}, s_{2}\right)$, the tariffs $\left(t_{1}, t_{2}\right)$, and the output of the other firm as given, each firm maximizes its profit:

$$
\pi_{i}=\left[p(Q)-c_{i}+s_{i}-t_{i}\right] q_{i}, \quad i=1,2,
$$

by choosing its own output. The first-order condition is given by ${ }^{7}$

$$
\frac{\partial \pi_{i}}{\partial q_{i}}=p^{\prime} q_{i}+p-c_{i}+s_{i}-t_{i}=0, \quad i=1,2
$$

The two first-order conditions in Equation 5 for the two firms can be solved for the Cournot equilibrium outputs $q_{1}^{*}\left(s_{1}, s_{2}, t_{1}, t_{2}\right)$ and $q_{2}^{*}\left(s_{1}, s_{2}, t_{1}, t_{2}\right)$. Totally differentiating Equation 5 , the following comparative statics results can be obtained:

$$
\begin{aligned}
& \frac{\partial q_{i}^{*}}{\partial t_{i}}=-\frac{\partial q_{i}^{*}}{\partial s_{i}}=\frac{p^{\prime \prime} q_{j}^{*}+2 p^{\prime}}{\Delta_{1}}<0 \\
& \frac{\partial q_{j}^{*}}{\partial t_{i}}=-\frac{\partial q_{j}^{*}}{\partial s_{i}}=-\frac{p^{\prime \prime} q_{j}^{*}+p^{\prime}}{\Delta_{1}}>0, \quad i, j=1,2 \text { and } i \neq j
\end{aligned}
$$

\footnotetext{
${ }^{5}$ The formal proof is available from the authors upon request.

${ }^{6}$ We thank a referee for providing the explanation.

${ }^{7}$ It is easy to show that the second-order condition is satisfied.
} 
Equations 6.1 and 6.2 show that an increase in tariff on firm $i$ will reduce $q_{i}^{*}$ but increase $q_{j}^{*}$. The equations also show that $\partial\left(q_{1}^{*}+q_{2}^{*}\right) / \partial t_{i}=p^{\prime} / \Delta_{1}<0$, i.e., the total output decreases as $t_{i}$ increases. It is easy to show further that the export subsidy $s_{i}$ has the opposite effects: it increases the output of firm $i$ and the total output, but it decreases the output of firm $j$.

In the third stage, country $\mathrm{M}$ sets tariffs $t_{1}$ and $t_{2}$ to maximize its national welfare, which is defined as the sum of consumer surplus and tariff revenue:

$$
W_{M}^{d}\left(s_{1}, s_{2}, t_{1}, t_{2}\right)=\int_{0}^{Q^{*}} p(x) d x-p\left(Q^{*}\right) Q^{*}+t_{1} q_{1}^{*}+t_{2} q_{2}^{*}
$$

The first-order conditions for maximization are given by:

$$
\frac{\partial W_{M}^{d}}{\partial t_{i}}=-p^{\prime} Q^{*} \frac{\partial Q^{*}}{\partial t_{i}}+q_{i}^{*}+t_{1} \frac{\partial q_{1}^{*}}{\partial t_{i}}+t_{2} \frac{\partial q_{2}^{*}}{\partial t_{i}}=0, \quad i=1,2 .
$$

Define $g_{i j}=\partial^{2} W_{M}^{d} / \partial t_{i} \partial t_{j}, i, j=1,2$. The second-order conditions, $g_{11}<0, g_{22}<0$, are assumed. Solving the two conditions in Equation 7 for the two tariff rates simultaneously yields the optimal discriminatory tariffs:

$$
t_{i}^{*}=-p^{\prime} q_{i}^{*}-p^{\prime \prime}\left(q_{1}^{* 2}+q_{2}^{* 2}\right), \quad i=1,2
$$

By using Equation 5, the difference between the two tariff rates is equal to

$$
t_{i}^{*}-t_{j}^{*}=p^{\prime}\left(q_{j}^{*}-q_{i}^{*}\right)=\frac{1}{2}\left[\left(c_{j}-s_{j}\right)-\left(c_{i}-s_{i}\right)\right], \quad i, j=1,2 \text { and } i \neq j .
$$

Hwang and Mai's (1991) 50\% rule states that with constant marginal costs but no export subsidies, the difference between the optimal tariffs chosen by the importing country is half of that of the marginal costs. Equation 8 is a simple extension of their result in the presence of export subsidies: the difference between the tariff rates on the goods from countries 1 and 2 is half of the difference between the effective marginal costs of the firms. Differentiate both sides of Equation 8 with respect to $s_{i}$ to give

$$
\frac{\partial\left(t_{i}^{*}-t_{j}^{*}\right)}{\partial s_{i}}=\frac{1}{2}, \quad i, j=1,2 \text { and } i \neq j .
$$

Equation 9 shows that a small rise in the subsidy rate imposed by one of the countries leads to a change in the tariff rate differential by half of the change in the subsidy rate.

Totally differentiating Equation 7 with respect to $s_{1}$ yields

$$
\left[\begin{array}{ll}
g_{11} & g_{12} \\
g_{21} & g_{22}
\end{array}\right]\left[\begin{array}{l}
\partial t_{1}^{*} / \partial s_{1} \\
\partial t_{2}^{*} / \partial s_{1}
\end{array}\right]=\left[\begin{array}{l}
-\partial^{2} W_{M}^{d} / \partial t_{1} \partial s_{1} \\
-\partial^{2} W_{M}^{d} / \partial t_{2} \partial s_{1}
\end{array}\right]=\left[\begin{array}{l}
g_{11}-\partial q_{1}^{*} / \partial t_{1} \\
g_{12}-\partial q_{1}^{*} / \partial t_{2}
\end{array}\right]
$$

For "stability", it is assumed that $\Delta_{3} \equiv g_{11} g_{22}-g_{12} g_{21}>0$. Solving Equation 10, we get

$$
\begin{aligned}
& \frac{\partial t_{1}^{*}}{\partial s_{1}}=1+\frac{1}{\Delta_{3}}\left(g_{12} \frac{\partial q_{1}^{*}}{\partial t_{2}}-g_{22} \frac{\partial q_{1}^{*}}{\partial t_{1}}\right) \\
& \frac{\partial t_{2}^{*}}{\partial s_{1}}=\frac{1}{\Delta_{3}}\left(g_{12} \frac{\partial q_{1}^{*}}{\partial t_{1}}-g_{11} \frac{\partial q_{1}^{*}}{\partial t_{2}}\right) .
\end{aligned}
$$

The signs of $\partial t_{1}^{*} / \partial s_{1}$ and $\partial t_{2}^{*} / \partial s_{1}$ are in general ambiguous. For the same reason, the signs of $\partial t_{1}^{*} / \partial s_{2}$ and $\partial t_{2}^{*} / \partial s_{2}$ are in general ambiguous.

Lemma 1. (a) If $g_{12} \leq 0$, then $0<\partial t_{j}^{*} / \partial s_{i}<\partial t_{i}^{*} / \partial s_{i}<1$. (b) If $g_{12}>0$, because $\left|g_{i i}\right|>\left|g_{i j}\right|$, then $\partial t_{j}^{*} / \partial s_{i}<\partial t_{i}^{*} / \partial s_{i}<1$. (c) If the demand function is linear, then $\partial t_{i}^{*} / \partial s_{i}=3 / 8>0$ and $\partial t_{j}^{*} / \partial s_{i}=-1 / 8<$ $0, i, j=1,2$ and $i \neq j$. 
The proof of this lemma is straightforward and is omitted here.

In the second stage, although fully aware of the effect of its policy on the tariffs set in the next stage, each exporting country sets its own export subsidy to maximize its national welfare, taking the other country's export subsidy as given, where the national welfare is the profit of its firm less the export subsidy payment:

$$
W_{i}^{d}=\left[p\left(Q^{*}\right)-c_{i}+s_{i}-t_{i}^{*}\right] q_{i}^{*}-s_{i} q_{i}^{*}, \quad i=1,2 .
$$

The first-order condition is given by

$$
\begin{aligned}
\frac{\partial W_{i}^{d}}{\partial s_{i}} & =-q_{i}^{*} \frac{\partial t_{i}^{*}}{\partial s_{i}}-s_{i}\left(\frac{\partial q_{i}^{*}}{\partial t_{i}} \frac{\partial t_{i}^{*}}{\partial s_{i}}+\frac{\partial q_{i}^{*}}{\partial t_{j}} \frac{\partial t_{j}^{*}}{\partial s_{i}}+\frac{\partial q_{i}^{*}}{\partial s_{i}}\right)+p^{\prime} q_{i}^{*}\left(\frac{\partial q_{j}^{*}}{\partial t_{i}} \frac{\partial t_{i}^{*}}{\partial s_{i}}+\frac{\partial q_{j}^{*}}{\partial t_{j}} \frac{\partial t_{j}^{*}}{\partial s_{i}}+\frac{\partial q_{j}^{*}}{\partial s_{i}}\right) \\
& =0, \quad i, j=1,2 \text { and } i \neq j .
\end{aligned}
$$

Assume again the second-order conditions and a globally unique Nash equilibrium in the export subsidy policy game. Define the following variables for country $i: P S_{i}=q_{i}^{*} p^{\prime}\left(\partial q_{j}^{*} / \partial s_{i}\right), O T_{i}=$ $q_{i}^{*}\left[p^{\prime}\left(\partial q_{j}^{*} / \partial t_{i}\right)-1\right]\left(\partial t_{i}^{*} / \partial s_{i}\right), C T_{i}=q_{i}^{*} p^{\prime}\left(\partial q_{j}^{*} / \partial t_{j}\right)\left(\partial t_{j}^{*} / \partial s_{i}\right)$, and

$$
\gamma_{i}=\frac{\partial q_{i}^{*}}{\partial t_{i}} \frac{\partial t_{i}^{*}}{\partial s_{i}}+\frac{\partial q_{i}^{*}}{\partial t_{j}} \frac{\partial t_{j}^{*}}{\partial s_{i}}+\frac{\partial q_{i}^{*}}{\partial s_{i}}, \quad i, j=1,2 \text { and } i \neq j
$$

Variables $P S_{i}, O T_{i}$, and $C T_{i}$ are interpreted as the profit-shifting effect, own-tariff effect, and crosstariff effect of an increase in $s_{i}$ on the welfare of country $i$. Condition 6.2 implies that $P S_{i}>0$, a result well-known in the literature. $O T_{i}$ has the opposite sign to $\partial t_{i}^{*} / \partial s_{i}$, whereas $C T_{i}$ has the same sign as $\partial t_{j}^{*} / \partial s_{i}$. Because the signs of $\partial t_{i}^{*} / \partial s_{i}$ and $\partial t_{j}^{*} / \partial s_{i}$ are generally ambiguous, the own-tariff and crosstariff effects have ambiguous signs as well.

Denote the export subsidy chosen by country $i$ under a discriminatory tariff regime as $s_{i}^{d}$. From condition 11 we can get

$$
s_{i}^{d}=\frac{P S_{i}+O T_{i}+C T_{i}}{\gamma_{i}}
$$

It is shown in the Appendix that $\gamma_{i}>0$. The sign of $s_{i}^{d}$ thus depends on the sign of the total effect, $P S_{i}+O T_{i}+C T_{i}$. Let us define the following condition:

Condition C. One or more of the following is satisfied: (a) $\partial t_{j}^{*} / \partial s_{i} \geq 0$ for $i, j=1,2$, and $i \neq j$; or (b) $\partial\left(t_{i}^{*}+t_{j}^{*}\right) / \partial s_{i} \geq 0, i, j=1,2$ and $i \neq j$; or (c) the demand function is linear.

Note that by Lemma 1 (a), Condition C (a) implies Condition C (b), and that by Lemma 1 (c), Condition $\mathrm{C}$ (c) implies Condition $\mathrm{C}(\mathrm{b})$. The reverse, however, is not true, meaning that there are cases in which Condition $\mathrm{C}$ (b) but not $\mathrm{C}$ (a) or $\mathrm{C}$ (c) holds. From Lemma 1, we know that the case when $\partial t_{i}^{*} / \partial s_{i}<0$ and $\partial t_{j}^{*} / \partial s_{i}>0$ (i.e., $O T_{i}>0$ and $C T_{i}>0$ ) is ruled out. Condition $\mathrm{C}$ (b) rules out the case when both $\partial t_{i}^{*} / \partial s_{i}$ and $\partial t_{j}^{*} / \partial s_{i}$ are negative (i.e., $O T_{i}>0$ and $C T_{i}<0$ ). Thus, if Condition $\mathrm{C}$ is satisfied, it must be the case that $O T_{i}<0$, implying that the exporting country favors an export tax for the own-tariff effect. Although the cross-tariff effect is non-negative under Condition $C$ (a), and maybe negative under Condition $\mathrm{C}(\mathrm{b})$, we show in the Appendix that the negative own-tariff effect dominates the other two effects so that the total effect is negative. Thus, $s_{i}^{d}<0$, implying that each exporting country favors an export tax. We now have the following proposition:

Proposition 1. In the sequential game under a discriminatory tariff regime in which export subsidies/taxes are chosen before the tariffs, the optimal policy for each exporting country is an export tax if Condition $\mathrm{C}$ is satisfied. 
Proof. See the Appendix.

Proposition 1 is an interesting result. When the government of an exporting country is choosing an export subsidy, it will take into consideration how a subsidy may affect the output of the other firm (the profit-shifting effect), the tariff imposed by the importing country on its export (the own-tariff effect), and the tariff imposed on its rival's export (the cross-tariff effect). In general, the sign of the total effect is ambiguous. Proposition 1 states the conditions under which the profit-shifting effect (and maybe the cross-tariff effect as well) will encourage the government to impose an export subsidy, whereas the own-tariff effect will lead to an export tax, and the own-tariff effect dominates so that the government of an exporting country will choose an export tax. Under these conditions, the BranderSpencer argument for an export subsidy is dominated by the government's desire to avoid a high tariff on its export.

It is also clear from the above analysis that if the importing country uses a uniform tariff regime, the own-tariff effect can never be dominant because the same tariff rate is always imposed on the products from both exporting countries.

If export subsidies and tariffs are chosen simultaneously, the above analysis implies that the optimal policy for each exporting country is an export subsidy because there exists only the profitshifting effect. This result has been shown in Gatsios (1990).

\section{Uniform or Discriminatory Tariffs?}

In this section we examine the welfare impacts of these two tariff regimes to all these countries. To do that, we consider a special case in which the two exporting countries are identical, i.e., $c_{1}=c_{2}{ }^{8}{ }^{8}$ As before, the fixed costs of the firms are assumed to be zero.

Because the two firms are identical, the exporting countries will choose the same subsidy rate under a uniform tariff regime. However, even under a discriminatory tariff regime, by Equation 8 , which states that $t_{1}^{*}=t_{2}^{*}$ if and only if $s_{1}=s_{2}$, the two exporting countries will still choose the same subsidy rate, knowing that the importing country will respond with the same tariff rate on their exports. Of course, what the exporting countries choose (and thus how the importing country responds) under a uniform tariff regime is not the same as what they do under a discriminatory tariff regime. Denote the common, noncooperative subsidy rate chosen by the exporting countries as $s^{d}$ and $s^{u}$ under a discriminatory and a uniform tariff regime, respectively. If Condition $\mathrm{C}$ holds, from Proposition 1, we know that $s^{d}<0<s^{u}$. Even if Condition $\mathrm{C}$ does not hold, it can be shown that $s^{d}<$ $s^{u}$. ${ }^{9}$ The intuition can be provided by Choi (1995). Choi shows that a lower marginal cost technology will be chosen under a uniform tariff regime. If we interpret an export subsidy as a way to reduce the marginal cost of a firm, then the exporting country would provide a higher export subsidy to reduce the marginal cost of its firm under a uniform tariff regime. Thus, $s^{d}<s^{u}$.

Denote the maximum welfare level of the importing country under a uniform or discriminatory tariff regime by $W_{M}^{u}\left(s_{1}, s_{2}\right)$ or $W_{M}^{d}\left(s_{1}, s_{2}\right)$, respectively, when the exporting countries choose subsidy rates of $s_{1}$ and $s_{2}$. For the importing country, as long as the exporting countries choose the same subsidy rate, its welfare is independent of the tariff regimes, i.e., $W_{M}^{d}(s, s)=W_{M}^{u}(s, s)$. Moreover, it is straightforward to show that, under either tariff regime, a rise in the export subsidy rate simultaneously

\footnotetext{
${ }^{8}$ In doing so, we eliminate the effects of different levels of productivity of the two exporting firms and concentrate more on the interactions among the countries.

${ }^{9}$ The formal proof is available from the authors upon request.
} 
chosen by both exporting countries, with country $\mathrm{M}$ choosing the optimal tariff, will benefit country $\mathrm{M}$. The intuition is that a simultaneous rise in the export subsidies will lower the price of the product, thus benefiting the importing country. Thus, we have $W_{M}^{d}\left(s^{d}, s^{d}\right)=W_{M}^{u}\left(s^{d}, s^{d}\right)<W_{M}^{u}\left(s^{u}, s^{u}\right)$, implying that the importing country prefers a uniform tariff regime. We have the following proposition:

Proposition 2. Suppose that the two exporting countries are identical. The importing country will optimally choose a uniform tariff regime.

It is worthwhile to mention that even if the importing country cared only about either consumer surplus or tariff revenue, it would still prefer a uniform tariff regime. Because $s^{d}<s^{u}$, consumer surplus is higher under a uniform tariff regime because a higher export subsidy leads to a lower market price and a greater output. On the other hand, more tariff revenue would be generated under a uniform tariff regime because of a greater output and a higher tariff imposed. ${ }^{10}$ Under a uniform tariff regime, the effective marginal cost of a firm is lower than that under a discriminatory tariff regime. Applying the results in Gatsios (1990) and Hwang and Mai (1991), we know that the importing country will impose a higher tariff under the former than under the latter. Because we assume identical costs, the importing country will impose the same tariff rate on both exporting countries even under a discriminatory tariff regime. Therefore, there is no loss in tariff revenue foregone under a uniform tariff regime because of the lack of discretionary power to impose different tariffs.

We now turn to the welfare effects of the tariff regimes on the exporting countries. Suppose that the exporting countries can cooperate and choose the export subsidy to maximize the joint welfare, $\left(W_{1}+W_{2}\right)$. The first-order condition for country $i$ when choosing $s_{i}$ to maximize the joint welfare of the exporting countries is given by $\partial\left(W_{1}+W_{2}\right) / \partial s_{i}=0, i=1,2$. Denote the common, cooperative export subsidy rate for each exporting country by $\tilde{s}$. Note that this subsidy rate is independent of the tariff regime because in either regime the same subsidy rate will be chosen for both exporting countries and the importing country will react with a common tariff rate. We have the following proposition:

Proposition 3. Suppose that the two exporting countries are identical. Given Condition C, $\tilde{s}<$ $s^{d}<0<s^{u}$, and the exporting countries prefer a discriminatory tariff regime.

Proof. See the Appendix.

Note that the ranking of the two tariff regimes for the two exporting countries depends on the ranking of the export subsidy rates. If Condition $\mathrm{C}$ holds, the two exporting countries, when acting cooperatively, will choose an export tax higher than what they will do independently under a discriminatory tariff regime. Thus, they will prefer a discriminatory tariff regime, choosing an export tax, to a uniform tariff regime, in which they choose an export subsidy. In this case, they will not like the tariff regime the importing country prefers. If, however, Condition $\mathrm{C}$ does not hold, it is possible that all three countries would prefer a uniform tariff regime.

\section{Concluding Remarks}

This paper examines the policy interactions among three countries: two exporting countries and one importing country. While the exporting countries choose an export subsidy policy, the importing country uses tariffs to extract rents from the two oligopolistic firms. All countries are allowed to

\footnotetext{
${ }^{10}$ Horiba and Tsutsui (2000) examine the effects of the tariff regimes on the long-run capacity decision of the exporting firms. They show the same result, that the equilibrium uniform tariff is higher than the discriminatory one.
} 
choose appropriate policies in a four-stage game, which permits us to examine the interactions among the governments and the choice of relevant strategic trade policies.

As is well known in the literature and from the work of Brander and Spencer (1985), exporting countries have the temptation to use an export subsidy to shift profit from a rival firm to their own firms. In the present model, an export subsidy could have other impacts that are not so desirable for an exporting country. In particular, under a discriminatory tariff regime, an export subsidy could cause a sufficiently large tariff to be imposed on the export of a country's firm to severely hurt the competitiveness of the firm. Under certain plausible conditions, including the use of discriminatory tariffs by the importing country, the optimal export subsidy for each exporting country is negative, suggesting that an export tax should be used.

We also compared the uniform and discriminatory tariff regimes in terms of the welfare of the countries. We found out that, at least in the case when the two exporting countries are identical, the importing country would choose a uniform tariff regime whereas the export countries prefer a discriminatory tariff regime. For the importing country, this result, which is consistent with countries' willingness to apply the MFN clause of the GATT/WTO, may seem to be contrary to the usual belief that a discriminatory tariff regime should dominate a uniform tariff regime because under the former the country can also choose the same tariffs. Our result suggests that this preconception does not hold in the present model because the exporting countries react with export subsidies under a uniform tariff regime but possibly with export taxes under a discriminatory tariff regime.

\section{Appendix}

Proof of Propostrton 1. The profit-shifting effect is known to be positive, $P S_{i}>0$. The signs of own-tariff and cross-tariff effects are ambiguous. The sum of them is equal to

$$
\begin{aligned}
O T_{i}+C T_{i} & =q_{i}^{*}\left[\left(p^{\prime} \frac{\partial q_{j}^{*}}{\partial t_{i}}-1\right) \frac{\partial t_{i}^{*}}{\partial s_{i}}+p^{\prime} \frac{\partial q_{j}^{*}}{\partial t_{j}} \frac{\partial t_{j}^{*}}{\partial s_{i}}\right] \\
& =q_{i}^{*}\left[-\left(\frac{p^{\prime \prime} q_{j}^{*}+p^{\prime \prime} Q^{*}+4 p^{\prime}}{p^{\prime \prime} Q^{*}+3 p^{\prime}}\right) \frac{\partial t_{i}^{*}}{\partial s_{i}}+\left(\frac{p^{\prime \prime} q_{i}^{*}+2 p^{\prime}}{p^{\prime \prime} Q^{*}+3 p^{\prime}}\right)\left(\frac{\partial t_{i}^{*}}{\partial s_{i}}-\frac{1}{2}\right)\right] \\
& =-q_{i}^{*}\left[2\left(\frac{p^{\prime \prime} q_{j}^{*}+p^{\prime}}{p^{\prime \prime} Q^{*}+3 p^{\prime}}\right) \frac{\partial t_{i}^{*}}{\partial s_{i}}+\frac{1}{2}\left(\frac{p^{\prime \prime} q_{i}^{*}+2 p^{\prime}}{p^{\prime \prime} Q^{*}+3 p^{\prime}}\right)\right]
\end{aligned}
$$

which may be positive or negative, depending on the values of $\partial t_{i}^{*} / \partial s_{i}$ and $\partial t_{j}^{*} / \partial s_{i}$. In case (a) of Condition $C, \partial t_{j}^{*} / \partial s_{i} \geq 0$, so $C T_{i} \geq 0$. From Equation 9 we know that $\partial t_{j}^{*} / \partial s_{i} \geq 0$ implies $1 / 2 \leq \partial t_{i}^{*} / \partial s_{i}<1$, so $O T_{i}<0$. The two tariff effects in Equation Al reduce to $O T_{i}+C T_{i} \leq-q_{i}^{*}\left[p^{\prime \prime}\left(1 / 2 q_{i}^{*}+q_{j}^{*}\right)+2 p^{\prime}\right] /\left(p^{\prime \prime} Q^{*}+3 p^{\prime}\right)<0$. Thus, the sum of all three effects $P S_{i}+O T_{i}+$ $C T_{i} \leq-q_{i}^{*}\left(1 / 2 p^{\prime \prime} q_{i}^{*}+p^{\prime}\right) /\left(p^{\prime \prime} Q^{*}+3 p^{\prime}\right)<0$.

Suppose now that $\partial t_{j}^{*} / \partial s_{i}<0$ while Condition $\mathrm{C}(\mathrm{b})$ holds, i.e., $\partial t_{i}^{*} / \partial s_{i}+\partial t_{j}^{*} / \partial s_{i} \geq 0$. Combining with Equation 9 , we have $1 / 4 \leq \partial t_{i}^{*} / \partial s_{i}<1 / 2$, so $C T_{i}<0$ and $O T_{i}<0$. The two tariff effects in Equation Al reduce to $O T_{i}+C T_{i} \leq-q_{i}^{*} / 2$. Because the profit-shifting effect is $P S_{i}=q_{i}^{*}\left(p^{\prime \prime} q_{j}+p^{\prime}\right) /\left(p^{\prime \prime} Q+3 p^{\prime}\right)<q_{i}^{*} / 2$, the sum of all three effects is again negative. In case (c) of Condition $\mathrm{C}$, the demand function is linear. We showed earlier that it implies that $\partial t_{i}^{*} / \partial s_{i}+\partial t_{j}^{*} / \partial s_{i}>0$. Thus, again, the sum of all three effects is negative. Tuming to the denominator in Equation 12, we have

$$
\begin{aligned}
\gamma_{i} & =\frac{\partial q_{i}^{*}}{\partial t_{i}} \frac{\partial t_{i}^{*}}{\partial s_{i}}+\frac{\partial q_{i}^{*}}{\partial t_{j}} \frac{\partial t_{j}^{*}}{\partial s_{i}}+\frac{\partial q_{i}^{*}}{\partial s_{i}} \\
& =\left[\frac{p^{\prime \prime} q_{j}^{*}+2 p^{\prime}}{p^{\prime}\left(p^{\prime \prime} Q^{*}+3 p^{\prime}\right)}\right]\left(\frac{\partial t_{i}^{*}}{\partial s_{i}}-1\right)-\left[\frac{p^{\prime \prime} q_{i}^{*}+2 p^{\prime}}{p^{\prime}\left(p^{\prime \prime} Q^{*}+3 p^{\prime}\right)}\right]\left(\frac{\partial t_{i}^{*}}{\partial s_{i}}-\frac{1}{2}\right) \\
& =\left[\frac{p^{\prime \prime}\left(q_{j}^{*}-q_{i}^{*}\right)+p^{\prime}}{p^{\prime}\left(p^{\prime \prime} Q^{*}+3 p^{\prime}\right)}\right]\left(\frac{\partial t_{i}^{*}}{\partial s_{i}}-1\right)-\frac{\left(p^{\prime \prime} q_{i}^{*}+p^{\prime}\right)}{2 p^{\prime}\left(p^{\prime \prime} Q^{*}+3 p^{\prime}\right)}>0
\end{aligned}
$$


because $\partial t_{i}^{*} / \partial s_{i}<1$ from Lemma 1. Thus, if Condition C is satisfied, $P S_{i}+O T_{i}+C T_{i}<0$ and $\gamma_{i}>0$. By Equation 12, the optimal subsidy $s_{i}^{d}<0$ for $i=1,2$.

PROOF OF PROPOSTION 3. Consider a discriminatory tariff regime. From Equation 11, we have

$$
\left.\frac{\partial W_{i}^{d}}{\partial s_{i}}\right|_{s_{1}=s_{2}=s^{d}}=-q_{i}^{*} \frac{\partial t_{i}^{*}}{\partial s_{i}}+p^{\prime} q_{i}^{*} \delta_{i}-s^{d} \gamma_{i}=0,
$$

where $\delta_{i}=\left(\partial q_{j}^{*} / \partial t_{i}\right)\left(\partial t_{i}^{*} / \partial s_{i}\right)+\left(\partial q_{j}^{*} / \partial t_{j}\right)\left(\partial t_{j}^{*} / \partial s_{i}\right)+\left(\partial q_{j}^{*} / \partial s_{i}\right)$ and $\gamma_{i}=\left(\partial q_{i}^{*} / \partial t_{i}\right)\left(\partial t_{i}^{*} / \partial s_{i}\right)+\left(\partial q_{i}^{*} / \partial t_{j}\right)\left(\partial t_{j}^{*} / \partial s_{i}\right)+\left(\partial q_{i}^{*} / \partial s_{i}\right)$ Differentiating $W_{j}^{d}$ with respect to $s_{i}$ and evaluating at $s_{1}=s_{2}=s^{d}$, we have

$$
\left.\frac{\partial W_{j}^{d}}{\partial s_{i}}\right|_{s_{1}=s_{2}=s^{d}}=-q_{j}^{*} \frac{\partial t_{j}^{*}}{\partial s_{i}}+p^{\prime} q_{j}^{*} \gamma_{i}-s^{d} \delta_{i} .
$$

Because $q_{1}^{*}=q_{2}^{*}=Q^{*} / 2$, and $\delta_{i}-\gamma_{i}=1 /\left(2 p^{\prime}\right)<0$, we have

$$
\begin{aligned}
\frac{\partial W_{i}^{d}}{\partial s_{i}}-\left.\frac{\partial W_{j}^{d}}{\partial s_{i}}\right|_{s_{1}=s_{2}=s^{d}} & =-q_{i}^{*}\left(\frac{\partial t_{i}^{*}}{\partial s_{i}}-\frac{\partial t_{j}^{*}}{\partial s_{i}}\right)+\left(p^{\prime} q_{i}^{*}+s^{d}\right)\left(\delta_{i}-\gamma_{i}\right) \\
& =-\frac{q_{i}^{*}}{2}+\left(p^{\prime} q_{i}^{*}+s^{d}\right)\left(\frac{1}{2 p^{\prime}}\right) \\
& =\frac{s^{d}}{2 p^{\prime}}
\end{aligned}
$$

Equation $\mathrm{A} 2$ reduces to

$$
\left.\frac{\partial W_{j}^{d}}{\partial s_{i}}\right|_{s_{1}=s_{2}=s^{d}}=\left.\frac{\partial\left(W_{i}^{d}+W_{j}^{d}\right)}{\partial s_{i}}\right|_{s_{1}=s_{2}=s^{d}}=-\frac{s^{d}}{2 p^{\prime}} .
$$

Given Condition C, by Proposition 1, $s^{d}<0$. Evaluating at $s_{1}=s_{2}=s^{d}<0$, Equation A3 implies that $\partial\left(W_{i}^{d}+W_{j}^{d}\right)$ ) $\partial s_{i}<0$. Because the welfare function is assumed to be concave, the exporting countries cooperatively want to lower their subsidy rate from $s^{d}$, i.e., $\tilde{s}<s^{d}<0$.

Because $s^{u}>0$, we then have $\tilde{s}<s^{d}<0<s^{\mu}$. Following the fact that $W_{i}$ is at a maximum when $s=\tilde{s}$, concavity of the welfare function, and the ranking $\tilde{s}<s^{d}<0<s^{\mu}$, we have $W_{i}\left(s^{\mu}, s^{\mu}\right)<W_{i}\left(s^{d}, s^{d}\right)<W_{i}(\tilde{s}, \tilde{s}), i=1,2$. Therefore, given Condition $\mathrm{C}$, the exporting countries prefer a discriminatory tariff regime.

\section{References}

Brander, James A. 1995. Strategic trade policy. In Handbook of international economics 3, edited by G. Grossman and K. Rogoff. Amsterdam, New York, and Oxford: Elsevier, North-Holland, pp. 1395-455.

Brander, James A., and Barbara J. Spencer. 1985. Export subsidies and international market share rivalry. Journal of International Economics 18:83-100.

Choi, Jay P. 1995. Optimal tariffs and the choice of technology: Discriminatory tariffs vs. the "Most Favored Nation" clause. Journal of International Economics 38:143-60.

Eaton, Jonathan, and Gene M. Grossman. 1986. Optimal trade and industrial policy under oligopoly. Quarterly Journal of Economics 101:383-406.

Gatsios, Konstantine. 1990. Preferential tariffs and the 'Most Favoured Nation' principle: A note. Journal of International Economics 28:365-73.

Horiba, Yutaka, and Shunichi Tsutsui. 2000. International duopoly, tariff policy and the superiority of free trade. The Japanese Economics Review 51:207-20.

Horstmann, Ignatius J., and James R. Markusen. 1986. Up the average cost curve: Inefficient entry and the new protectionism. Journal of International Economics 20:225-47.

Hwang, Hong, and Chao-Cheng Mai. 1991. Optimum discriminatory tariffs under oligopolistic competition. Canadian Journal of Economics 24:693-702.

Saggi, Kamal. 2004. Tariffs and the most favored nation clause. Journal of International Economics 63:341-68.

Wong, Kar-yiu. 1995. International trade in goods and factor mobility. Cambridge, MA: MIT Press. 
Copyright of Southern Economic Journal is the property of Southern Economic Association and its content may not be copied or emailed to multiple sites or posted to a listserv without the copyright holder's express written permission. However, users may print, download, or email articles for individual use. 